\title{
Student perceptions of clinical experiences in endodontic access cavity preparations
}

SADJ May 2020, Vol. 75 No. 4 p198 - p205

P Gwengu', C Jonker ${ }^{2}$

\section{ABSTRACT}

\section{Objectives}

The aim of this study was to gain understanding into the perceptions of undergraduate dental students regarding their levels of competence and confidence when preparing endodontic access cavities.

\section{Materials and method}

Anonymous survey forms were given to 100 undergraduate dental students at Sefako Makgatho Health Sciences University, School of Oral Health Sciences. Students were asked to indicate their self-confidence level by using a 5 -point Likert scale as 'not confident', 'manageable', 'comfortable and confident',' extremely confident' and 'never done it'.

\section{Results}

The response rate was $75 \%$ out of 100 students. The majority of the participants (88\%) indicated that they would perform endodontic access cavity preparation with ease on anterior teeth and the lowest (43\%) confidence levels was indicated on multi-rooted posterior teeth.

\section{Keywords}

Perceptions, clinical experiences, endodontic access cavity preparation, teaching and learning.

\section{INTRODUCTION}

Endodontic treatment and management of patients is a multi-fold approach. It involves the complete debridement of infected tissues inside the root canal system and ultimately a root canal preparation which will meet biological and mechanical needs. ${ }^{1}$ The first step in treating an endodontically affected tooth is the preparation of a proper access cavity. ${ }^{1}$ The use of rotary burs to create endodontic access cavities or locating root canal orifices can cause serious iatrogenic damage to the tooth and greatly influence the prognosis and restorability. ${ }^{1}$

\section{Author affiliations:}

1. Pumela Gwengu: Dip OH, BDS, MPH, M Dent (Comm Dent), Department of Operative Dentistry, Sefako Makgatho Health Science University, Garankuwa, Pretoria, South Africa.

2. Casper Jonker: $B C H D$, Dip Odont, MSc, Department of Operative Dentistry, Sefako Makgatho Health Science University, Garankuwa, Pretoria, South Africa.

ORCID Number: 0000-0002-9110-5208

Corresponding author: Pumela Gwengu

Department of Operative Dentistry, Sefako Makgatho Health Science University, Garankuwa, Pretoria, South Africa.

Email: pumela.gwengu@smu.ac.za

Author contributions:

1. Pumela Gwengu: Principal researcher - $70 \%$, writing of the article - $60 \%$ and conceptual stage contribution - 10\%

2. Casper Jonker: Researcher $-30 \%$, writing of the article $-20 \%$, and conceptual stage contribution - $10 \%$
The use of rotary burs in an incorrect manner and misaligned angle of penetration is often a critical factor in iatrogenic tooth damage. ${ }^{2}$ To prevent adverse outcomes like these, appropriately designed pre-clinical teaching and learning strategies will be required.

Access cavity preparation is a crucial step to ensure successful root canal treatment. Incorrect techniques applied during the preparation of access cavities may lead to a variety of procedural accidents. These include perforations, destruction of large amounts of healthy tooth structure and instrument fractures. In order to prevent these complications, dental students need to become competent in preparing access cavities.

Patient safety has always been a concern during clinical teaching and learning of dental students. Thus the importance of ensuring that undergraduate students reach an acceptably high level of competence in their preclinical learning and skills development prior to them being allowed to manage and treat patients. ${ }^{3,4}$

At Sefako Makgatho University (SMU) Oral Health Centre, students have a very limited time to learn and practice preparation of access cavities in their preclinical sessions; nonetheless they are allowed to continue with their preclinical work for few additional sessions until they are ready to treat patients.

A need therefore will always exist to improve endodontic access cavity preparation skills of under-graduate dental students as they continue to manage complex clinical cases. Patient's safety, prevention of complications and procedural accidents are constantly emphasized during preclinical and clinical training.

Students at SMU are exposed to exponential clinical training as well as community outreach programmes. Dental students begin both their pre-clinical and didactic endodontic teaching in the fourth year of their 5-year Bachelor of Dental Surgery (BDS) degree. Dental students would prepare and fill six root canals from extracted single-rooted teeth and four extracted bi-rooted teeth during their preclinical training. Students need to complete access cavities in all ten extracted teeth (six anterior and four premolars). Instructions are given on both conventional stainless-steel files ( $k$-files) as well as rotary files and radiographic images are taken for preoperative diagnosis.

Teaching and training in endodontic discipline for BDS 4 students consists of two-hour theoretical lectures for 
a period of fifteen weeks, fourteen two-hour preclinical sessions for a period of four weeks and upon satisfactory completion of the preclinical work, students are allowed to treat patients for one three-hour clinical session weekly for a period of thirty weeks.

The main focus for BDS 4 students is clinical preparation of single-rooted anterior teeth (four incisors or canines) as well as bi-rooted posterior teeth (two premolars). Additional pre-clinical training in endodontics is done for BDS 5 students with one four-hour session weekly for a month. Fifth-year dental students would prepare and fill root canals of four extracted multi-rooted teeth (molars). The focus is on completion of the access cavity preparation on four extracted posterior teeth (molars) plus instructions are given by highly skilled clinicians on how to use the electronic apex locator and rotary files.

Management of more complex cases are carried out by fifth year dental students as part of comprehensive patient care under the supervision of experienced endodontic clinicians. An array of different clinical training platforms allows students to develop academically and professionally. The build-up of knowledge as well as clinical exposure to various oral diseases and conditions does assist in improving their clinical expertise.

Students in their fifth year of endodontic training receive further clinical exposure in access cavity preparation at the emergency clinic (Careline) where patients are seen for the first time. Difficult and extremely complex endodontic cases that necessitate management under Dental Operating Microscope (DOM) are referred and managed by experienced endodontic clinicians.

Student's opinions are important and are a critical aspect of academic course evaluation which can indicate where potential improvements in their Endodontic education and course outcomes can be addressed. However, in recent years more academics have begun to acknowledge the role played by students in providing course evaluation and inputs in a classroom environment. Evaluation processes must be timetabled and in-cooperated into the academic programme and completed independently and by other faculty members other than the course co-ordinators. Students in the higher learning environment must be encouraged to partake in these evaluation processes.

Student competence can be understood as a complex arrangement of a human being's skills that are called into play in a variety of situations. ${ }^{5}$ In fact, competence "carries the dual meaning that says there is a track record of such achievement (competent performance) and also that the individual has the capability to perform well in the future. It refers to good adaptation and not necessarily to superb achievement". ${ }^{5}$ Systematic competence constitutes an individual's skill in effectively planning his or her work as well as the mastery of relevant techniques. ${ }^{5}$

There are numerous innovative approaches to address the problem of teaching psychomotor skills to under graduate dental students, but none of these were specifi- cally focused on endodontic access cavity preparation. ${ }^{6}$ It is, however, well known that undergraduate dental students struggle with the transition of preclinical training to the clinical environment where they have to deal with complex challenges such access cavities on porcelain fused to metal crowns and other patientrelated factors. ${ }^{7,8}$ Learners are said to struggle with the skills obtained at the "School" and what they have learned, and transferring these skills and knowledge to the clinical or work environment. ${ }^{9}$

The validation for undertaking this study at Sefako Makgatho University (SMU) Oral Health Centre is based on the following aspects; BDS4 students have limited time to learn and practice preparation of access cavities in their preclinical sessions; secondly, BDS4 students are booked patients who already received emergency root canal treatments and access cavity has already been completed, hence this may impact students clinical skills in treating and managing complex and challenging endodontic clinical cases. The study aimed to investigate student's perceptions on their competency and confidence levels in access cavity preparation in endodontics at SMU oral health centre.

\section{METHODOLOGY}

Ethical clearance was obtained (SMUREC /D/181/2017) prior to commencement of the study.

A quantitative cross-sectional, observational survey was conducted. One hundred dental students were invited to partake on a voluntary basis. Each participant was requested to complete a self-administered questionnaire at that particular point of clinical training which was closer to the end of the second semester in the $4^{\text {th }}$ year and $5^{\text {th }}$ year of dental training. All dental students who were trained in endodontics consented to participate in the study and those students were in year 4 and 5 of their study. Dental students who were not trained in endodontics were excluded from the study.

\section{QUESTIONNAIRE}

A 26-question survey was developed based on past questionnaires that had been previously used successfully by Davey and others in 2014. ${ }^{10}$ It was designed specifically for the study in English, together with the information sheet and consent forms. The questionnaires were used to evaluate the responses from $4^{\text {th }}$ and $5^{\text {th }}$ year dental students using Likert scale format.

The first section of the questionnaire was on levels of competence and students rated their perceived competency levels using "unsure", "yes" and "no". ${ }^{10-14}$ The remainder of the questionnaire assessed students perceived levels of confidence and they classified this using a 5 -point Likert scale with answers as 'not confident', 'manageable', 'comfortable and confident', 'extremely confident' and 'never done it'. ${ }^{10-14}$

The questionnaire assessed students' experiences on: perceived competent levels on access cavity preparation and perceived competent levels on various endodontic tasks of creating access cavity. The closed-ended 
questions were used to obtain information on dental student's perceptions when performing endodontic access cavity preparations. Dental student's perception of their competence level was self-rated and scored in the assessment tool. Students were not coerced to answer in a particular way and this was ensured by making use of an independent research assistant.

A pilot test of randomly selected small group of five students from the fifth-year group was performed by the research assistant to determine feasibility, content clarity, the validity of the questionnaire and its acceptability so that potential problems could be identified and resolved before commencing the study itself.

The students who participated in the pilot study were voluntarily excluded from the main study. Some few questions were reviewed as per input from the participants of the pilot study. Sufficient time was allowed to create a relaxed environment without rushing or coercing students with an aim of obtaining a true reflection of their perceptions.

The background information regarding this research topic was introduced by the investigators to the participating students before consent was obtained. Response bias was addressed by reassuring participants of their anonymity and that their participation in the study was not going to influence students' academic outcome. Response bias from participants was also minimized by adding an "unsure" option in the questionnaire as part of response. Distribution and collection of the questionnaires was managed by the independent research assistant to minimize students fear.

\section{STATISTICAL ANALYSIS}

Data was first captured in Microsoft Excel 2016 before exporting to SPSS (Statistical Package for the Social Sciences version 20, (SPSS Inc., Chicago, II, USA) for analysis. Preliminary analysis of data was done where missing values and errors were checked and corrected. Reliability of the instrument was measured using Cronbach's Alpha. Two constructs (competency and confidence) were defined in the study. Competency and confidence scales recorded Cronbach's alpha values of $70.3 \%$ and $79.3 \%$ respectively. An overall Cronbach's alpha value of $77.2 \%$ was achieved. This is a good overall level of internal consistency which is above the $70.0 \%$ threshold.

Normality tests were performed using KolmogorovSmirnova and indicated that the data of the study was not normally distributed. Therefore, nonparametric statistics and tests (such as frequencies, percentages, Chi squared tests and Kruskal Wallis tests) were appropriate to use in the study as opposed to parametric tests.

\section{RESULTS}

The results of the pilot study were evaluated and the content was adjusted before the questionnaires were distributed the students. A total of 100 questionnaires were distributed to a target audience of 100 dental students in the Bachelor of Dental Science, BDS $4=50$ and BDS $5=50$ (notable excluding the five piloted students). Out of this total, 75 questionnaires were completed in full and returned. Each questionnaire took approximately fifteen minutes to complete. Research questionnaire was distributed and collected by a research assistant upon completion. This gives a response rate of $75 \%$ which was $72 \%$ for BDS 5: 36 (48\%) and $78 \%$ for BDS 4: 39 (52\%) (Table 1).

\begin{tabular}{|l|c|c|c|}
\hline \multicolumn{3}{|l|}{ Table 1. Students response rate. } \\
\hline Year & No. contacted & No. participated & Response (\%) \\
\hline A & 50 & 36 & 72.0 \\
\hline B & 50 & 39 & 78.0 \\
\hline Total & 100 & 75 & 75.0 \\
\hline
\end{tabular}

Perceptions of competence levels when performing endodontic access cavities on anterior and posterior teeth

Out of 75 who completed the questionnaire, 70 (93.3\%) confirmed that they were competent in endodontic access cavity preparation on anterior teeth and 47 (62.7\%) confirmed to be competent on the posterior teeth.

Of the 70 who confirmed that they were more competent in endodontic access cavity preparation on anterior teeth $36(48.0 \%)$ were fourth-year dental students and 34 (45.3\%) were fifth-year dental students. Of the 47 who confirmed that they were competent in endodontic access cavity preparation on posterior teeth $19(25.3 \%)$ were fourth-year dental students and 28 (37.3\%) were fifth-year dental students (Table 2).

\begin{tabular}{l|c|c|c|}
$\begin{array}{l}\text { Table 2. Students perceptions of their competence when performing } \\
\text { endodontic access cavities. }\end{array}$ & \multicolumn{1}{l|}{ Total } \\
$\begin{array}{l}\text { Do you feel competent when } \\
\text { performing endodontic access } \\
\text { cavities on }\end{array}$ & \multicolumn{2}{|c|}{ Years of Study } \\
\hline $\begin{array}{l}\text { An anterior tooth } \\
\text { Yes }\end{array}$ & $36(48.0 \%)$ & $34(45.3 \%)$ & $70(93.3 \%)$ \\
\hline No & $0(0.0 \%)$ & $0(0.0 \%)$ & $0(0.0 \%)$ \\
\hline Unsure & $3(4.0 \%)$ & $2(2.7 \%)$ & $5(6.7 \%)$ \\
\hline A posterior tooth & & & \\
\hline Yes & $19(25.3 \%)$ & $28(37.3 \%)$ & $47(62.7 \%)$ \\
\hline No & $13(17.3 \%)$ & $4(5.3 \%)$ & $17(22.7 \%)$ \\
\hline Unsure & $7(9.3 \%)$ & $4(5.3 \%)$ & $11(14.7 \%)$ \\
\hline A single-rooted posterior tooth & & & \\
\hline Yes & $33(44.0 \%)$ & $32(42.7 \%)$ & $65(86.7 \%)$ \\
\hline No & $3(4.0 \%)$ & $0(0.0 \%)$ & $3(4.0 \%)$ \\
\hline Unsure & $3(4.0 \%)$ & $4(5.3 \%)$ & $7(9.3 \%)$ \\
\hline A multi-rooted posterior tooth & & & \\
\hline Yes & $18(24.0 \%)$ & $24(32.0 \%)$ & $42(56.0 \%)$ \\
\hline No & $14(18.7 \%)$ & $5(6.7 \%)$ & $19(25.3 \%)$ \\
\hline Unsure & $7(9.3 \%)$ & $7(9.3 \%)$ & $14(18.7 \%)$ \\
\hline
\end{tabular}

Furthermore, a noticeable difference was observed between the perceived competence levels of the single rooted posterior teeth (BDS 4: 33 (44\%) \& BDS 5: 32 $(42.7 \%)$ and multi-rooted posterior teeth (BDS 4: 18 $(24.0 \%)$ \& BDS 5: 24 (32.0\%). However, none of the fifth-year dental students that reported that they were incompetent in performing endodontic access cavity on anterior teeth and a few of them 4 (5.3\%) confirmed that they were incompetent in endodontic access cavity on posterior teeth. 
A small number of fifth year dental students 2 (2.7\%) confirmed that they were not sure of their competency level for anterior teeth and 4 (5.3\%) for the posterior teeth (Figure 1).

\section{Perceptions of confidence levels when performing} endodontic access cavities on teeth with variable dental status

A certain number of fourth year dental students 10 (13.3\%) reported to be extremely confident when performing endodontic access cavity on anterior teeth whilst there was about $3(4.0 \%)$ students who were extremely confident in endodontic access cavity on posterior teeth (Table 3).

Additionally, there was only one $(1.3 \%) 5^{\text {th }}$ year dental students who reported that she/he was not confident in performing endodontic access cavity on posterior teeth.

There were some fourth-year dental students who stated that they never prepared endodontic access cavity on anterior teeth with massive carious lesion (BDS 4: 13 $(17.3 \%)$ and on posterior teeth with massive carious lesions (BDS 4: 12 (16.0\%).

Most students 33 (45.8\%) confirmed that that they never prepared endodontic access cavity on anterior teeth with gold inlays (BDS4: 22(30.6\%) and BDS 5: 11 (15.3\%).

Of the 43 (57.3\%) who confirmed that they never prepared endodontic access cavity on anterior teeth with metal, porcelain or in ceramic crowns, there were (BDS 4: 29 (38.7\%) \& BDS 5: 14 (18.7\%).
Of the $17(22.7 \%)$ who confirmed that they were extremely confident in endodontic access cavity on anterior teeth with fractured clinical crown, they were (BDS 4: 4 (5.3 \%) \& BDS 5: 13 (17.3\%).

\section{Perceptions of confidence levels when performing endodontic clinical stages during access cavity preparations}

Data revealed that there were 60 (80.0\%) dental students who reported that they were extremely confident in delivering local anaesthesia for anterior and 49 (65.3\%) were extremely confident for posterior teeth (Table 4).

Most dental students 45 (60.0\%) confirmed that they were extremely confident in rubber dam placement on anterior teeth; BDS 4: 20 (26.7\%) and BDS 5: 25 (33.3\%). There were about $20(26.7 \%)$ students who perceived themselves to be extremely confident in taking intra-oral $x$ rays for the purpose of diagnosing clinical crown length; BDS 4: 11 (14.7\%) and BDS 5: 9 (12.0\%) and there were about 12 (16\%) who were extremely confident and able to identify the depth of the access cavity on preoperative, intra-operative and post-operative $\mathrm{x}$-rays; BDS 4: $6(8.0 \%)$ and BDS 5: 6 (8.0\%).

Of the $30(40.0 \%)$ dental students out of 75 who confirmed that they were comfortable and confident in bur selection, these were BDS 4: 15 (20.0\%) and BDS 5: 15 (20.0\%). Fourteen (18.7\%) dental students reported that they were extremely confident in the creation of a coronal flare on anterior teeth; BDS 4: 6 (8.0\%) and BDS 5: 8 (10.7\%) and on posterior teeth BDS 4: 5 (6.7\%) and BDS 5: 1 (1.3\%). There were some students 10 (13.3\%) who confirmed that they have never done any coronal flare on posterior teeth; BDS 4: 9 (12.0\%) and BDS 5: 1 (1.3\%).
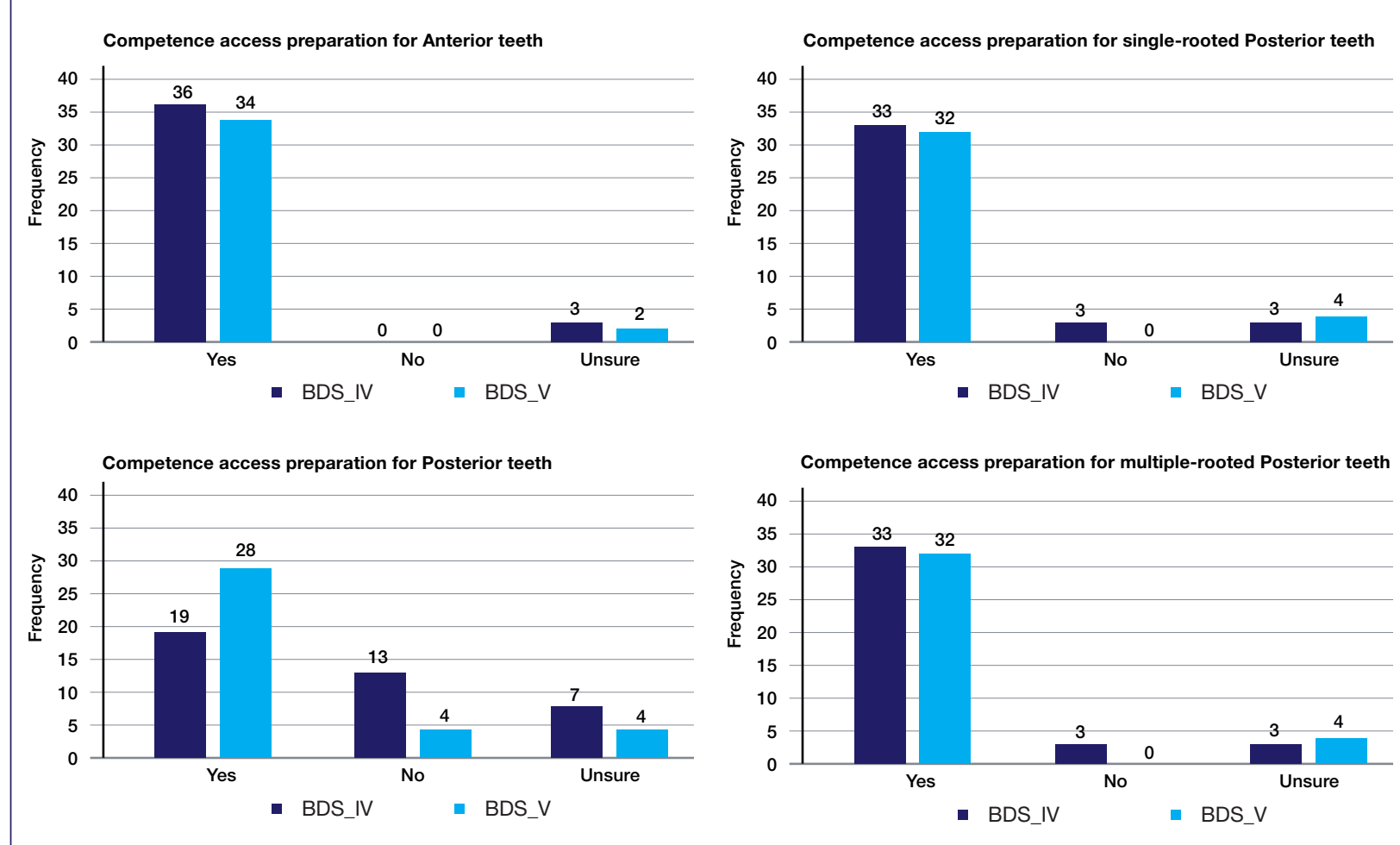

Figure 1. Students perceptions of their competence when performing endodontic access cavities. 
Thirty nine (52\%) dental students out of 75 reported that they were extremely confident in the placement of interappointment temporal restorations using Kalzinol and IRM; BDS 4: 17 (22.7\%) and BDS 5: 22 (29.3\%) with an exception of one (1.3\%) BDS 4 student who reported that she/he was not confident in placing a temporal restoration.

\section{Statistical analysis}

Kruskal-Wallis test was used to determine significant differences between the two groups (BDS 4 and BDS 5) on competency levels and confidence levels on access cavity preparations (Table 5). It was observed that there were significant $(p<0.05)$ differences between BDS 4 and BDS 5 on competency levels on access cavity preparations for posterior teeth. There was no statistical evidence to suggest any differences between the two groups on competency levels for anterior teeth, single rooted posterior and multi-rooted posterior teeth. There were highly statistically significant $(p<0.01)$ differences between BDS 4 and BDS 5 on confidence levels on access cavity preparations for anterior teeth with crowns (metal, porcelain and in Ceramic) and anterior teeth with massive carious lesions. Statistically significant $(p<0.05)$ differences were also observed on confidence levels on

\begin{tabular}{|c|c|c|c|}
\hline \multirow{2}{*}{$\begin{array}{l}\text { How confident do you feel when } \\
\text { performing endodontic access } \\
\text { cavities on }\end{array}$} & \multicolumn{2}{|c|}{ Years of Study } & \multirow{2}{*}{ Total } \\
\hline & $4^{\text {th }}$ & $5^{\text {th }}$ & \\
\hline \multicolumn{4}{|l|}{ An anterior tooth } \\
\hline Not confident at all & $0(0.0 \%)$ & $0(0.0 \%)$ & $0(0.0 \%)$ \\
\hline Manageable & $5(6.7 \%)$ & $4(5.3 \%)$ & $9(12.0 \%)$ \\
\hline Comfortable \& confident & $24(32.0 \%)$ & $16(21.3 \%)$ & $40(53.3 \%)$ \\
\hline Extremely confident & $10(13.3 \%)$ & $16(21.3 \%)$ & $26(34.7 \%)$ \\
\hline Never done it & $0(0.0 \%)$ & $0(0.0 \%)$ & $0(0.0 \%)$ \\
\hline \multicolumn{4}{|l|}{ A posterior tooth } \\
\hline Not confident at all & $5(6.7 \%)$ & $1(1.3 \%)$ & $6(8.0 \%)$ \\
\hline Manageable & $14(18.7 \%)$ & $13(17.3 \%)$ & $27(36.0 \%)$ \\
\hline Comfortable \& confident & $11(14.7 \%)$ & $20(26.7 \%)$ & $31(41.3 \%)$ \\
\hline Extremely confident & $3(4.0 \%)$ & $2(2.7 \%)$ & $5(6.7 \%)$ \\
\hline Never done it & $6(8.0 \%)$ & $0(0.0 \%)$ & $6(8.0 \%)$ \\
\hline \multicolumn{4}{|l|}{ A single-rooted posterior tooth } \\
\hline Not confident at all & $2(2.7 \%)$ & $0(0.0 \%)$ & $2(2.7 \%)$ \\
\hline Manageable & $6(8.0 \%)$ & $4(5.3 \%)$ & $10(13.3 \%)$ \\
\hline Comfortable \& confident & $22(29.3 \%)$ & $16(21.3 \%)$ & $38(50.7 \%)$ \\
\hline Extremely confident & $6(8.0 \%)$ & $16(21.3 \%)$ & $22(29.3 \%)$ \\
\hline Never done it & $3(4.0 \%)$ & $0(0.0 \%)$ & $3(4.0 \%)$ \\
\hline \multicolumn{4}{|l|}{ A multi-rooted posterior tooth } \\
\hline Not confident at all & $5(6.7 \%)$ & $2(2.7 \%)$ & $7(9.3 \%)$ \\
\hline Manageable & $14(18.7 \%)$ & $15(20.0 \%)$ & $29(38.7 \%)$ \\
\hline Comfortable \& confident & $10(13.3 \%)$ & $16(21.3 \%)$ & $26(34.7 \%)$ \\
\hline Extremely confident & $3(4.0 \%)$ & $3(4.0 \%)$ & $6(8.0 \%)$ \\
\hline Never done it & $7(9.3 \%)$ & $0(0.0 \%)$ & $7(9.3 \%)$ \\
\hline \multicolumn{4}{|l|}{$\begin{array}{l}\text { An anterior tooth with massive } \\
\text { carious lesion }\end{array}$} \\
\hline Not confident at all & $0(0.0 \%)$ & $1(1.3 \%)$ & $1(1.3 \%)$ \\
\hline Manageable & $7(9.3 \%)$ & $10(13.3 \%)$ & $17(22.7 \%)$ \\
\hline Comfortable \& confident & $14(18.7 \%)$ & $17(22.7 \%)$ & $31(41.3 \%)$ \\
\hline Extremely confident & $5(6.7 \%)$ & $8(10.7 \%)$ & $13(17.3 \%)$ \\
\hline Never done it & $13(17.3 \%)$ & $0(0.0 \%)$ & $13(17.3 \%)$ \\
\hline
\end{tabular}

access cavity preparations for posterior teeth with crowns (metal, porcelain and in Ceramic).

\section{DISCUSSION}

Dental student's evaluation input is important to improve the curriculum and to correct existing errors and to identify the missing elements of the curriculum. ${ }^{11}$ Student selfassessments of their own proficiency serve as helpful means to make a realistic evaluation of dental curricula and the assessment of the effectiveness of specific courses. Students questionnaire are one of the important tools that can be used in collecting data for the purpose of getting student's input. ${ }^{12}$ At Sefako Makgatho Health Science University where the study was conducted, curriculum reviews are done for both theoretical and clinical practise and these reviews includes dental students evaluation input.

Dental students are given enough opportunities to finetune their clinical skills in access cavity preparation during their professional training. Management of endodontic patients are carried out by fifth-year dental students as part of comprehensive patient care and they are supervised by experienced endodontic clinicians. These stu-

\begin{tabular}{|c|c|c|c|}
\hline \multirow{2}{*}{$\begin{array}{l}\text { How confident do you feel when } \\
\text { performing endodontic access } \\
\text { cavities on }\end{array}$} & \multicolumn{2}{|c|}{ Years of Study } & \multirow{2}{*}{ Total } \\
\hline & $4^{\text {th }}$ & $5^{\text {th }}$ & \\
\hline \multicolumn{4}{|l|}{$\begin{array}{l}\text { A posterior tooth with massive } \\
\text { carious lesion }\end{array}$} \\
\hline Not confident at all & $3(4.0 \%)$ & $5(6.7 \%)$ & $8(10.7 \%)$ \\
\hline Manageable & $11(14.7 \%)$ & $11(14.7 \%)$ & $22(29.3 \%)$ \\
\hline Comfortable \& confident & $9(12.0 \%)$ & $12(16.0 \%)$ & $21(28.0 \%)$ \\
\hline Extremely confident & $4(5.3 \%)$ & $7(9.3 \%)$ & $11(14.7 \%)$ \\
\hline Never done it & $12(16.0 \%)$ & $1(1.3 \%)$ & $13(17.3 \%)$ \\
\hline \multicolumn{4}{|l|}{$\begin{array}{l}\text { A heavily restored anterior tooth } \\
\text { with composite }\end{array}$} \\
\hline Not confident at all & $0(0.0 \%)$ & $1(1.3 \%)$ & $1(1.3 \%)$ \\
\hline Manageable & $14(18.7 \%)$ & $10(13.3 \%)$ & $24(32.0 \%)$ \\
\hline Comfortable \& confident & 19 (25.3\%) & $13(17.3 \%)$ & $32(42.7 \%)$ \\
\hline Extremely confident & $1(1.3 \%)$ & $11(14.7 \%)$ & $12(16.0 \%)$ \\
\hline Never done it & $5(6.7 \%)$ & $1(1.3 \%)$ & $6(8.0 \%)$ \\
\hline \multicolumn{4}{|l|}{$\begin{array}{l}\text { An anterior tooth restored with } \\
\text { gold inlay }\end{array}$} \\
\hline Not confident at all & $0(0.0 \%)$ & $1(1.4 \%)$ & $1(1.4 \%)$ \\
\hline Manageable & $8(11.1 \%)$ & $10(13.9 \%)$ & $18(25.0 \%)$ \\
\hline Comfortable \& confident & $7(9.7 \%)$ & $9(12.5 \%)$ & $16(22.2 \%)$ \\
\hline Extremely confident & $2(2.8 \%)$ & $2(2.8 \%)$ & $4(5.6 \%)$ \\
\hline Never done it & $22(30.6 \%)$ & $11(15.3 \%)$ & $33(45.8 \%)$ \\
\hline \multicolumn{4}{|l|}{$\begin{array}{l}\text { A crowned anterior tooth with any } \\
\text { of these (porcelain or in ceramic } \\
\text { or metal) }\end{array}$} \\
\hline Not confident at all & $0(0.0 \%)$ & $2(2.7 \%)$ & $2(2.7 \%)$ \\
\hline Manageable & $2(2.7 \%)$ & $9(12.0 \%)$ & $16(21.3 \%)$ \\
\hline Comfortable \& confident & $7(9.3 \%)$ & $9(12.0 \%)$ & $16(21.3 \%)$ \\
\hline Extremely confident & $1(1.3 \%)$ & $2(2.7 \%)$ & $3(4.0 \%)$ \\
\hline Never done it & $29(38.7 \%)$ & $14(18.7 \%)$ & $43(57.3 \%)$ \\
\hline \multicolumn{4}{|l|}{$\begin{array}{l}\text { A crowned posterior tooth with any } \\
\text { of these (porcelain or in ceramic } \\
\text { or metal) }\end{array}$} \\
\hline Not confident at all & $2(2.7 \%)$ & $1(1.3 \%)$ & $3(4.0 \%)$ \\
\hline Manageable & $2(2.7 \%)$ & $7(9.3 \%)$ & $9(12.0 \%)$ \\
\hline Comfortable \& confident & $72(2.0 \%)$ & $6(8.0 \%)$ & $8(10.0 \%)$ \\
\hline Extremely confident & $1(1.3 \%)$ & $1(1.3 \%)$ & $2(2.7 \%)$ \\
\hline Never done it & $32(42.7 \%)$ & $21(28.0 \%)$ & $53(70.7 \%)$ \\
\hline
\end{tabular}


dents are also exposed to integrated clinical dentistry and students are responsible for all dental treatments of the patients that are assigned to them.

The study aimed at understanding student's perceptions in terms of their confidence and competence levels in their clinical experiences whilst performing endodontic access cavities. These findings on competency on access cavity preparation on anterior teeth, single-rooted and multi-rooted posterior teeth are in line with theoretical expectations as it is stated in other studies. ${ }^{13}$

In this study, all dental students were competent in access cavity preparation on anterior teeth as opposed to posterior teeth. This is not unexpected because

\begin{tabular}{|c|c|c|c|}
\hline \multirow{2}{*}{$\begin{array}{l}\text { How confident do you feel when } \\
\text { performing these endodontic } \\
\text { clinical stages }\end{array}$} & \multicolumn{2}{|c|}{ Years of Study } & \multirow{2}{*}{ Total } \\
\hline & $4^{\text {th }}$ & $5^{\text {th }}$ & \\
\hline \multicolumn{4}{|l|}{$\begin{array}{l}\text { Delivery of local anesthesia for an } \\
\text { anterior tooth }\end{array}$} \\
\hline Not confident at all & $0(0.0 \%)$ & $0(0.0 \%)$ & $0(0.0 \%)$ \\
\hline Manageable & $1(1.3 \%)$ & $1(1.3 \%)$ & $2(2.3 .0 \%)$ \\
\hline Comfortable \& confident & $5(6.7 \%)$ & $7(9.3 \%)$ & $12(16.0 \%)$ \\
\hline Extremely confident & $30(40.0 \%)$ & $30(40.0 \%)$ & $60(80.0 \%)$ \\
\hline Never done it & $1(1.3 \%)$ & $0(0.0 \%)$ & $1(1.3 \%)$ \\
\hline \multicolumn{4}{|l|}{$\begin{array}{l}\text { Delivery of local anesthesia for a } \\
\text { posterior tooth }\end{array}$} \\
\hline Not confident at all & $0(0.0 \%)$ & $0(0.0 \%)$ & $0(0.0 \%)$ \\
\hline Manageable & $3(4.0 \%)$ & $3(4.0 \%)$ & $6(8.0 \%)$ \\
\hline Comfortable \& confident & $9(12.0 \%)$ & $8(10.7 \%)$ & $17(22.7 \%)$ \\
\hline Extremely confident & $24(32.0 \%)$ & $25(33.3 \%)$ & $49(65.3 \%)$ \\
\hline Never done it & $3(4.0 \%)$ & $0(0.0 \%)$ & $3(4.0 \%)$ \\
\hline \multicolumn{4}{|l|}{$\begin{array}{l}\text { Rubber dam placement on an } \\
\text { anterior tooth }\end{array}$} \\
\hline Not confident at all & $0(0.0 \%)$ & $1(1.3 \%)$ & $1(1.3 \%)$ \\
\hline Manageable & $4(5.3 \%)$ & $3(4.0 \%)$ & 7 (9.3\%) \\
\hline Comfortable \& confident & $15(20.0 \%)$ & $7(9.3 \%)$ & $22(29.3 \%)$ \\
\hline Extremely confident & $20(26.7 \%)$ & $25(33.3 \%)$ & $45(60.0 \%)$ \\
\hline Never done it & $0(0.0 \%)$ & $0(0.0 \%)$ & $0(0.0 \%)$ \\
\hline \multicolumn{4}{|l|}{$\begin{array}{l}\text { Rubber dam placement on a pos- } \\
\text { terior tooth }\end{array}$} \\
\hline Not confident at all & $0(0.0 \%)$ & $4(5.3 \%)$ & $4(5.3 \%)$ \\
\hline Manageable & $6(8.0 \%)$ & $8(10.7 \%)$ & $14(18.7 \%)$ \\
\hline Comfortable \& confident & $13(17.3 \%)$ & $8(10.7 \%)$ & $2128.0 \%)$ \\
\hline Extremely confident & $19(25.3 \%)$ & $16(21.3 \%)$ & $35(46.7 \%)$ \\
\hline Never done it & $1(1.3 \%)$ & $0(0.0 \%)$ & $1(1.3 \%)$ \\
\hline \multicolumn{4}{|l|}{$\begin{array}{l}\text { Pre-operative, intra-operative } \\
\text { and post-operative radiographic } \\
\text { interpretation of size, shape and } \\
\text { content of pulpal chamber }\end{array}$} \\
\hline Not confident at all & $1(1.4 \%)$ & $1(1.4 \%)$ & $2(2.7 \%)$ \\
\hline Manageable & $9(12.2 \%)$ & $4(5.4 \%)$ & $13(17.6 \%)$ \\
\hline Comfortable \& confident & $23(31.1 \%)$ & $26(35.1 \%)$ & $49(66.2 \%)$ \\
\hline Extremely confident & $6(8.1 \%)$ & $4(5.4 \%)$ & $10(13.5 \%)$ \\
\hline Never done it & $0(0.0 \%)$ & $0(0.0 \%)$ & $0(0.0 \%)$ \\
\hline \multicolumn{4}{|l|}{$\begin{array}{l}\text { Pre-operative, intra-operative } \\
\text { and post-operative radiographic } \\
\text { interpretation for measuring clinical } \\
\text { crown length }\end{array}$} \\
\hline Not confident at all & $0(0.0 \%)$ & $1(1.3 \%)$ & $1(1.3 \%)$ \\
\hline Manageable & $9(12.0 \%)$ & $6(8.0 \%)$ & $15(20.0 \%)$ \\
\hline Comfortable \& confident & $19(25.3 \%)$ & $20(26.7 \%)$ & $39(52.0 \%)$ \\
\hline Extremely confident & $11(14.7 \%)$ & $9(12.0 \%)$ & $20(26.7 \%)$ \\
\hline Never done it & $0(0.0 \%)$ & 0 (0.0\%) & $0(0.0 \%)$ \\
\hline
\end{tabular}

many studies have shown that molar endodontics is a complex procedure in which students had the least confidence. ${ }^{12-14}$ Davey and other researchers in 2015 were also in agreement to the fact that molar endodontics is the most difficult clinical procedure. ${ }^{10}$

Endodontic treatment can be quite challenging and may pose difficulties both in terms of clinical conditions of that particular tooth such as massive carious lesion, restored with clinical crowns and morphological characteristics of that particular tooth. ${ }^{12}$

When different types of teeth were scored by dental students in terms of self-confidence levels, it was observed that molar endodontic access cavity preparation yielded relatively lower values and these results are consistent with the results of previous studies. ${ }^{13,15,16}$

Notable from the results of this study, is that most of the fourth-year dental students have never attempted complex access cavity preparation. This assertion has been demonstrated by the highly statistically significant levels between BDS 4 and BDS 5 on access cavity preparations of anterior teeth with crowns (metal, porcelain and in Ceramic).

\begin{tabular}{|c|c|c|c|}
\hline \multirow{2}{*}{$\begin{array}{l}\text { How confident do you feel when } \\
\text { performing these endodontic } \\
\text { clinical stages }\end{array}$} & \multicolumn{2}{|c|}{ Years of Study } & \multirow{2}{*}{ Total } \\
\hline & $4^{\text {th }}$ & $5^{\text {th }}$ & \\
\hline \multicolumn{4}{|l|}{$\begin{array}{l}\text { Pre-operative, intra-operative } \\
\text { and post-operative radiographic } \\
\text { interpretation of depth and size of } \\
\text { access cavity }\end{array}$} \\
\hline Not confident at all & $1(1.3 \%)$ & $1(1.3 \%)$ & $2(2.0 \%)$ \\
\hline Manageable & $12(16.0 \%)$ & $5(6.7 \%)$ & $17(22.7 \%)$ \\
\hline Comfortable \& confident & $19(25.3 \%)$ & $24(32.0 \%)$ & $43(57.3 \%)$ \\
\hline Extremely confident & $6(8.0 \%)$ & $6(8.0 \%)$ & $12(16.0 \%)$ \\
\hline Never done it & $1(1.3 \%)$ & $0(0.0 \%)$ & $1(1.3 \%)$ \\
\hline \multicolumn{4}{|l|}{$\begin{array}{l}\text { At selecting the type of a bur that } \\
\text { you would use }\end{array}$} \\
\hline Not confident at all & $1(1.3 \%)$ & $1(1.3 \%)$ & $2(2.7 \%)$ \\
\hline Manageable & $8(10.7 \%)$ & $6(8.0 \%)$ & $14(18.7 \%)$ \\
\hline Comfortable \& confident & $15(20.0 \%)$ & $15(20.0 \%)$ & $30(40.0 \%)$ \\
\hline Extremely confident & $15(20.0 \%)$ & $14(18.7 \%)$ & $29(38.7 \%)$ \\
\hline Never done it & $0(0.0 \%)$ & $0(0.0 \%)$ & $0(0.0 \%)$ \\
\hline \multicolumn{4}{|l|}{$\begin{array}{l}\text { At coronal flare creation for an } \\
\text { anterior tooth }\end{array}$} \\
\hline Not confident at all & $3(4.0 \%)$ & $0(0.0 \%)$ & $3(4.0 \%)$ \\
\hline Manageable & $11(14.7 \%)$ & $13(17.3 \%)$ & $24(32.0 \%)$ \\
\hline Comfortable \& confident & $17(22.7 \%)$ & $14(18.7 \%)$ & $31(41.3 \%)$ \\
\hline Extremely confident & $6(8.0 \%)$ & $8(10.7 \%)$ & $14(18.7 \%)$ \\
\hline Never done it & $2(2.7 \%)$ & $1(1.3 \%)$ & $3(4.0 \%)$ \\
\hline \multicolumn{4}{|l|}{$\begin{array}{l}\text { At coronal flare creation for a } \\
\text { posterior tooth }\end{array}$} \\
\hline Not confident at all & $3(4.0 \%)$ & $2(2.7 \%)$ & $5(6.7 \%)$ \\
\hline Manageable & $12(16.0 \%)$ & $20(26.7 \%)$ & $32(42.7 \%)$ \\
\hline Comfortable \& confident & $10(13.3 \%)$ & $12(16.0 \%)$ & $22(29.3 \%)$ \\
\hline Extremely confident & $5(6.7 \%)$ & $1(1.3 \%)$ & $6(8.0 \%)$ \\
\hline Never done it & $9(12.0 \%)$ & $1(1.3 \%)$ & $10(13.3 \%)$ \\
\hline \multicolumn{4}{|l|}{$\begin{array}{l}\text { At placing an inter-appointment } \\
\text { temporal restoration }\end{array}$} \\
\hline Not confident at all & $1(1.3 \%)$ & $0(0.0 \%)$ & $1(1.3 \%)$ \\
\hline Manageable & $6(8.0 \%)$ & $5(6.7 \%)$ & $11(14.7 \%)$ \\
\hline Comfortable \& confident & $15(20.0 \%)$ & $8(10.7 \%)$ & $23(30.7 \%)$ \\
\hline Extremely confident & $17(22.7 \%)$ & $22(29.3 \%)$ & $39(52.0 \%)$ \\
\hline Never done it & $0(0.0 \%)$ & $1(1.3 \%)$ & $1(1.3 \%)$ \\
\hline
\end{tabular}


Furthermore, highly statistically significant level were observed between the two groups on access cavity preparations for anterior teeth with massive carious lesions. This also confirms the validation of the study because fourth-year dental students do not rotate at an emergency unit (Careline), where most of the emergency root canal treatments, access cavity preparations on teeth with various clinical status, complex and challenging clinical cases are being managed. Therefore, this absence of rotation by fourth-year dental students at Careline must be seen as a shortcoming of our institutional planning and curriculum design.

Students also reported lower confidence levels in delivery of local anaesthetics on posterior teeth, these findings are in line with previous studies whereby it was stated by students that the most difficult areas in terms of obtaining anaesthesia was on posterior teeth. ${ }^{17,18}$ In addition, students confirmed lower confidence levels in rubber dam placement for posterior teeth.

A previous study by Tanalp and other authors in 2013 stated that rubber dam application was one of the endodontic clinical steps where students reported the lowest confidences. ${ }^{12}$ However, rubber dam application is a prerequisite and students are not allowed to complete their treatments without the use of this significant apparatus at Sefako Makgatho Health Science University. Rubber dam is also an indispensable element of endodontic clinical practice and is not only a valuable tool but an ethical and medico-legal prerequisite for dental practitioners. $^{12}$

In our study, it was also observed that confidence levels varied in some instances according to both the year of study as well as the practical steps of endodontic access cavity. When summarizing the results of the study, it was observed that molars were the most difficult teeth group for all steps of endodontic treatment.

\begin{tabular}{|c|c|c|c|c|}
\hline Significant attribute & $\begin{array}{l}\text { Chi- } \\
\text { Square }\end{array}$ & df & $\begin{array}{l}\text { Asymp. } \\
\text { Sig. }\end{array}$ & Significance \\
\hline Anterior teeth competences & 0.136 & 1 & 0.71 & NS \\
\hline Posterior teeth competences & 3.935 & 1 & 0.05 & ** \\
\hline $\begin{array}{l}\text { Single rooted posterior teeth com- } \\
\text { petences }\end{array}$ & 0.186 & 1 & 0.67 & NS \\
\hline $\begin{array}{l}\text { Multi-rooted posterior teeth compe- } \\
\text { tences }\end{array}$ & 0.940 & 1 & 0.33 & NS \\
\hline Anterior teeth confidences & 2.148 & 1 & 0.14 & NS \\
\hline Posterior teeth confidences & 0.012 & 1 & 0.91 & NS \\
\hline $\begin{array}{l}\text { Single rooted posterior teeth com- } \\
\text { petences }\end{array}$ & 3.004 & 1 & 0.08 & * \\
\hline $\begin{array}{l}\text { Multi-rooted posterior teeth compe- } \\
\text { tences }\end{array}$ & 0.216 & 1 & 0.64 & NS \\
\hline $\begin{array}{l}\text { Anterior teeth with massive carious } \\
\text { lesion confidences }\end{array}$ & 7.198 & 1 & 0.01 & *** \\
\hline $\begin{array}{l}\text { Posterior teeth with massive carious } \\
\text { lesion confidences }\end{array}$ & 3.486 & 1 & 0.06 & * \\
\hline $\begin{array}{l}\text { Anterior teeth with a huge composite } \\
\text { restoration confidences }\end{array}$ & 0.783 & 1 & 0.38 & NS \\
\hline $\begin{array}{l}\text { Anterior teeth with gold inlay confi- } \\
\text { dences }\end{array}$ & 3.728 & 1 & 0.05 & * \\
\hline $\begin{array}{l}\text { A crowned anterior teeth with porce- } \\
\text { lain or in Ceram or metal }\end{array}$ & 11.157 & 1 & 0.00 & *** \\
\hline $\begin{array}{l}\text { A crowned posterior teeth with porce- } \\
\text { lain or in Ceram or metal }\end{array}$ & 4.497 & 1 & 0.03 & ** \\
\hline \multicolumn{5}{|c|}{${ }^{\star} \mathrm{p}<0.1 ;{ }^{\star \star} \mathrm{p}<0.05 ;{ }^{\star \star \star} \mathrm{p}<0.01$; NS not significant } \\
\hline
\end{tabular}

The significant variations that are shown between BDS 4 and BDS 5 students in this study is a clear indication of non-clinical exposure to complex and challenging endondontic cases at an emergency unit. The findings may prompt Sefako Makgatho Health Science University to reconsider the endodontic theoretical and clinical course by in cooperating the necessary curriculum changes. Changing of the endodontic programme may also assist students to be able to progress in clinical knowledge and expertise. Endodontic education at this institution should be improved by adding the clinical rotations for BDS 4 students at an emergency unit and gradually introduce them to complex access cavity preparations.

\section{CONCLUSION}

The results showed students' lower confidence levels in the more challenging aspects of endodontic access cavity preparation and these findings varied in some instances according to the year of study, complexity of the case as well as the practical steps of endodontic access cavity.

The significance of this research study is to provide the dental institution with valuable information that can improve student's skills on endodontic access cavity preparation regarding the readiness of students to manage complex and challenging endodontic access cavities.

\section{References}

1. Tsesis I, Fuss Z. Diagnosis and treatment of accidental root perforations. Endodontic Topics. 2006; 13: 95-107.

2. American Association of Endodontists. Glossary of endodontic terms, $9^{\text {th }}$ edition. Chicago: American Association of Endodontists, 2015

3. Fugill M. Defining the purpose of phantom head. European Journal of Dental Education. 2013; 17, e1-e4.

4. Maran NJ, Glavin RJ. Low- to high-fidelity simulation - a continuum of medical education? Medical Education. 2007; 37 (Suppl. 1), 22- 8.

5. Masten AS, Coatsworth J. The Development of Competence in Favorable and Unfavorable Environments: Lessons from Research on Successful Children. The American psychologist. 1998; 53. 205-20.

6. Arena G, Kruger E, Holley D, Millar S, Tennant M. Western Australian dental graduates' perception of preparedness to practice: A five-year follow-up. Journal of Dental Education. 2007; 71:1217-22.

7. Aly M, Willems G, Carels C, Elen J. Instructional multimedia programs for self-directed learning in undergraduate and postgraduate training in orthodontics. European Journal of Dental Education. 2003; 7: 20-26.

8. Divaris K, Mafla A, Villa-Torres L, Sanchez-Molina M, Gallego-Gomez C, Velez-Jaramillo L Tamayo-Cardona J, Perez-Cepeda D, Vergara-Mercado M, Simancas-Pallares M and Polychronopoulou A. Psychological distress and its correlates among dental students: a survey of 17 Colombian dental schools. BMC Medical Education. 2013; 13: 91.

9. Polychronopoulou A, Divaris K. A longitudinal study of Greek dental student's perceived sources of stress. Journal of Dental Education. 2010; 74: 524-30.

10. Konkola R, Tuomi-Gröhn T, Lambert P, Ludvigsen S. Promoting learning and transfer between school and workplace. Journal of Education and Work. 2007; 20: 211-28. 
11. Davey J, Bryant ST, Dummer PMH. The confidence of undergraduate dental students when performing root canal treatment and their perception of the quality of endodontic education. European Journal of Dental education. 2014; 19: 229-34.

12. Mirza MB. Difficulties Encountered during Transition from Preclinical to Clinical Endodontics among Salman bin Abdul Aziz University Dental Students. Journal of International Oral Health. 2015; 7:22-7.

13. Tanalp J, Güven EP, Oktay I. Evaluation of dental students' perception and self-confidence levels regarding endodontic treatment. European Journal of Dentistry. 2013; 7: 218-24.

14. Honey J, Lynch CD, Burke FM, Gilmour AS. Ready for practice? A study of confidence levels of final year dental students at Cardiff University and University College Cork. European Journal of Dental Education. 2011; 15: 98-103.

15. Ayhan T, Barut G, Tanalp J. The self-confidence levels of senior dental students during endodontic treatment procedures. Turkish Endodontic Journal. 2006; 1(1): 1922.
16. Patel J, Fox K, Grieveson B, Youngson CC. Undergraduate training as preparation for vocational training in England: a survey of vocational dental practitioners' and their trainers' views. British Dental Journal. 2006; Suppl: 9-15.

17. Arena G, Kruger E, Holley D, Millar S, Tennant M. Western Australian dental graduates' perception of preparedness to practice: A five-year follow-up. Journal of Dental Education. 2007; 71: 1217-22.

18. Bigby J, Reader A, Nusstein J, Beck M. Anesthetic efficacy of lidocaine/meperidine for inferior alveolar nerve blocks in patients with irreversible pulpitis. Journal of Endodontics. 2007; 33: 7-10.

\section{Do the CPD questionnaire on page 223}

The Continuous Professional Development (CPD) section provides for twenty general questions and five ethics questions. The section provides members with a valuable source of CPD points whilst also achieving the objective of CPD, to assure continuing education. The importance of continuing professional development should not be underestimated, it is a career-long obligation for practicing professionals.

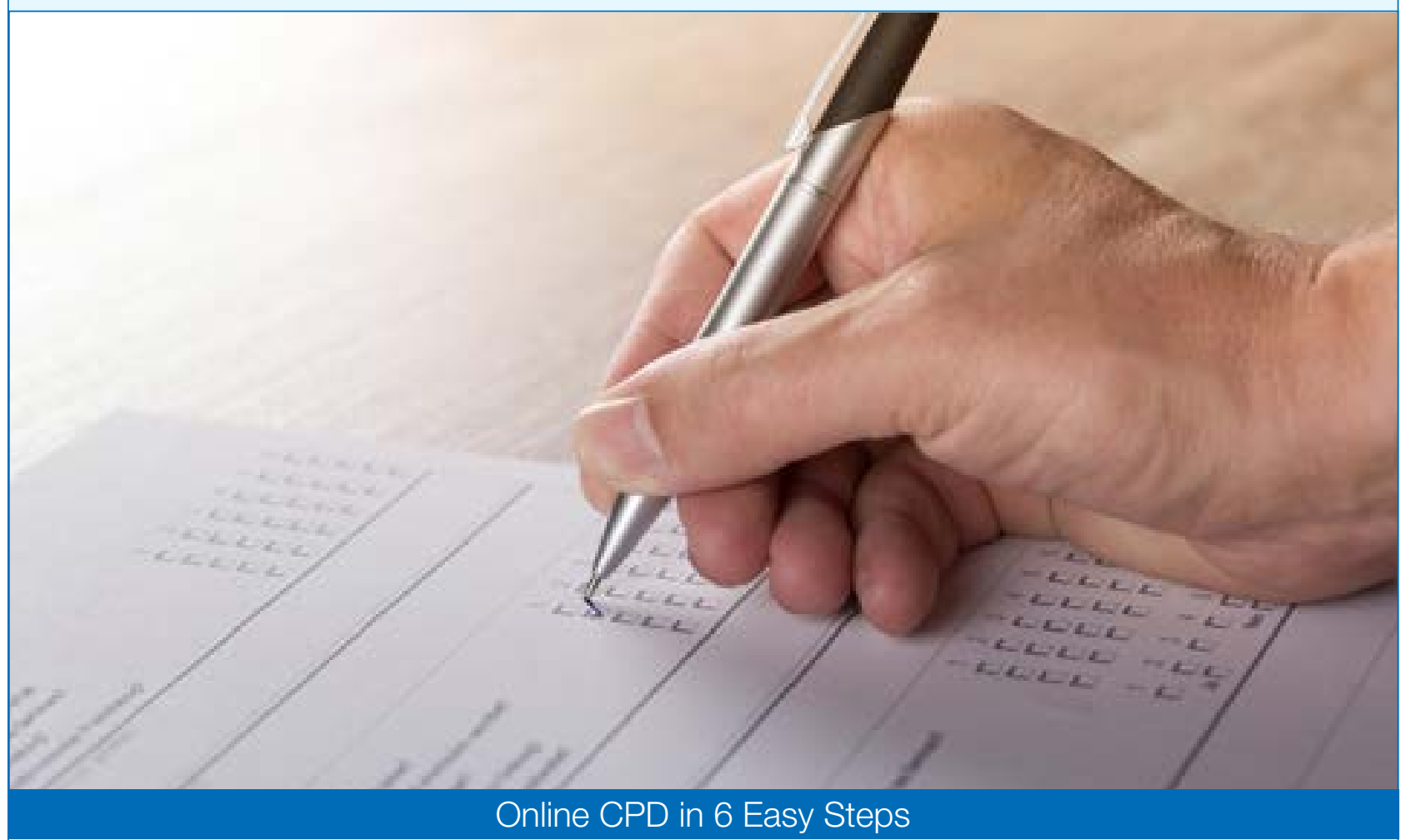

1 Go to the SADA website www.sada.co.za.

2 Log into the 'member only' section with your unique SADA username and password.

3 Select the CPD navigation tab.

4 Select the questionnaire that you wish to complete.

5 Enter your multiple choice answers. Please note that you have two attempts to obtain at least $70 \%$.

6 View and print your CPD certificate. 